\title{
Column ozone and aerosol optical properties retrieved from direct solar irradiance measurements during SOLVE II
}

\author{
W. H. Swartz ${ }^{1}$, J.-H. Yee ${ }^{1}$, R. E. Shetter ${ }^{2}$, S. R. Hall ${ }^{2}$, B. L. Lefer ${ }^{2,}$, J. M. Livingston ${ }^{3}$, P. B. Russell ${ }^{4}$, E. V. Browell ${ }^{5}$, \\ and M. A. Avery ${ }^{5}$ \\ ${ }^{1}$ The Johns Hopkins University Applied Physics Laboratory, Laurel, Maryland, USA \\ ${ }^{2}$ National Center for Atmospheric Research, Boulder, Colorado, USA \\ ${ }^{3}$ SRI International, Menlo Park, California, USA \\ ${ }^{4}$ NASA Ames Research Center, Moffett Field, California, USA \\ ${ }^{5}$ NASA Langley Research Center, Hampton, Virginia, USA \\ *now at: University of Houston, Department of Geosciences, Houston, Texas, USA
}

Received: 21 September 2004 - Published in Atmos. Chem. Phys. Discuss.: 9 November 2004

Revised: 28 January 2005 - Accepted: 18 February 2005 - Published: 1 March 2005

\begin{abstract}
Direct observation of the Sun at large solar zenith angles during the second SAGE III Ozone Loss and Validation Experiment (SOLVE II)/Validation of International Satellites and study of Ozone Loss (VINTERSOL) campaign by several instruments provided a rich dataset for the retrieval and analysis of line-of-sight column composition, intercomparison, and measurement validation. A flexible, multi-species spectral fitting technique is presented and applied to spectral solar irradiance measurements made by the NCAR Direct beam Irradiance Atmospheric Spectrometer (DIAS) on-board the NASA DC-8. The approach allows for the independent retrieval of $\mathrm{O}_{3}, \mathrm{O}_{2} \cdot \mathrm{O}_{2}$, and aerosol optical properties, by constraining Rayleigh extinction. We examine the 19 January 2003 and 6 February 2003 flights and find very good agreement of $\mathrm{O}_{3}$ and $\mathrm{O}_{2} \cdot \mathrm{O}_{2}$ retrievals with forward-modeling calculations, even at large solar zenith angles, where refraction is important. Intercomparisons of retrieved ozone and aerosol optical thickness with results from the Ames Airborne Tracking Sunphotometer (AATS-14) are summarized.
\end{abstract}

\section{Introduction}

For over a century, the composition of Earth's atmosphere has been inferred from the atmospheric transmission of stellar, lunar, and solar light. Many ground-based instruments have been developed for the measurement of ozone, $\mathrm{NO}_{2}$, and other trace gas column densities using directattenuated and scattered ultraviolet (UV)/visible light (e.g., Dobson, 1957; Brewer, 1973; Pommereau and Goutail, 1988;

Correspondence to: $\mathrm{W} . \mathrm{H}$. Swartz

(bill.swartz@jhuapl.edu)
Roscoe et al., 1994). These instruments exploit differential transmission that results from the spectral features of constituent absorption cross sections. Modern moderate- and high-resolution spectrometers have been used in numerous ground-, balloon-, aircraft-, and space-based applications.

The second SAGE III Ozone Loss and Validation Experiment (SOLVE II)/Validation of International Satellites and study of Ozone Loss (VINTERSOL) campaign, based in Kiruna, Sweden during January-February 2003, comprised coordinated measurements at high northern latitudes using the NASA DC-8 aircraft, balloon platforms, and groundbased instruments. One of the major scientific objectives of the campaign was validation of the Stratospheric Aerosol and Gas Experiment (SAGE) III solar occultation satellite instrument, which measures ozone and aerosols based on their spectral attenuation of direct solar irradiance (NASA, 2002). A number of species, including ozone and aerosols, were measured by a suite of spectrometers and photometers on board the DC- 8 making direct solar observations, providing correlative data for intercomparison and satellite validation.

Simultaneous retrieval of ozone, aerosols, and other constituents along the solar line of sight (LOS), particularly at large solar zenith angles (SZAs), requires accurate determination of Rayleigh extinction and is complicated by the wavelength-dependent refractive bending of the solar flux (Yee et al., 2002). Yee et al. and DeMajistre and Yee (2002) developed a multi-spectral fitting technique for the retrieval of ozone from satellite stellar occultation measurements. This technique was used during the first SOLVE campaign to determine ozone loss within the polar vortex (Swartz et al., 2002) and has been intercompared with other satellite, aircraft, and ground-based measurements (Vervack et al., 2003; Newman et al., 2002; Grant et al., 2003).

(C) 2005 Author(s). This work is licensed under a Creative Commons License. 
In this paper, we adapt the multi-wavelength/multi-species retrieval used in the stellar occultation technique to retrieve slant column $\mathrm{O}_{3}$ and $\mathrm{O}_{2} \cdot \mathrm{O}_{2}$ (also referred to as " $\mathrm{O}_{4}$ " in the literature) densities and aerosol optical thickness (AOT, and its wavelength dependence) from NCAR Direct beam Irradiance Atmospheric Spectrometer (DIAS) solar irradiance data from the DC-8 during SOLVE II. The retrievals are available for intercomparison with SAGE III and with instruments co-manifested on the DC-8. Intercomparisons of retrieved ozone and AOT with results from the Ames Airborne Tracking Sunphotometer (AATS-14) instrument are summarized here and presented in more detail elsewhere (Livingston et al., 2005; Russell et al., 2004). Further, this work forms the foundation upon which we can use other data, both in situ aircraft (e.g., lidar) and analyses of satellite datasets (e.g., three-dimensional ozone fields reconstructed from proxy maps (Randall et al., 2005)), to evaluate the impact of ozone LOS spatial inhomogeneity on satellite retrievals (manuscript in preparation, "Y05-ms"1).

\section{Solar spectral irradiance and composition retrieval}

\subsection{Irradiance model}

The direct solar spectral irradiance $L^{\circ}(\lambda)$ incident on an observer is

$L^{\circ}(\lambda)=L_{\infty}(\lambda) \exp \left(-\int_{\text {observer }}^{\text {Sun }}\left[\sum_{i=1}^{\text {species }} \sigma_{i}\left(\lambda, s_{\lambda}\right) n_{i}\left(s_{\lambda}\right)\right] d s_{\lambda}\right)$,

where $L_{\infty}$ is the extraterrestrial (ET) solar irradiance, $\sigma_{i}$ and $n_{i}$ are the extinction cross section and the number density for species $i$, respectively, and $s_{\lambda}$ is the wavelength-dependent, refracted line-of-sight slant path from the observer to the Sun at wavelength $\lambda$. The vertical density gradient of the atmosphere causes refraction, particularly at altitudes below the mid-stratosphere, which bends the light path, with short wavelengths bent more than longer wavelengths.

Depending on the wavelength range under consideration, numerous species attenuate the transmitted spectral solar flux, including molecular (Rayleigh) scattering, primarily by $\mathrm{N}_{2}$ and $\mathrm{O}_{2}$, absorption by $\mathrm{O}_{2}, \mathrm{O}_{3}, \mathrm{O}_{2} \cdot \mathrm{O}_{2}$ collisional pairs, $\mathrm{NO}_{2}, \mathrm{BrO}, \mathrm{OClO}$, and $\mathrm{SO}_{2}$, and extinction by clouds and aerosols. Integration in Eq. (1) along the line-of-sight path gives

$L^{\circ}(\lambda)=L_{\infty}(\lambda) \exp \left(-\sum_{i=1}^{\text {species }} \sigma_{i}^{\mathrm{eff}}(\lambda) N_{i}(\lambda)\right)$

\footnotetext{
${ }^{1}$ Yee, J.-H., Swartz, W. H., DeMajistre, R., Shetter, R. E., Randall, C. E., and Lloyd, S. A.: Effects of field inhomogeneity on high-latitude ozone retrievals from spaceborne remote sensing measurements, (Y05-ms), in preparation, 2005.
}

where $\sigma_{i}^{\text {eff }}$ and $N_{i}$ are the wavelength-dependent effective cross section and LOS column abundance of species $i$, respectively. Cross sections vary along the light path as temperature and pressure change, but an "effective" value may be determined at any particular wavelength, based on the temperature/pressure along the LOS path, weighted by the relative strength of the absorption. $N_{i}$ is wavelength-dependent, because the refracted light path varies with wavelength, but this wavelength dependence is negligible except at very large SZAs.

The measured irradiance, $L_{\text {meas }}$, depends on the characteristics of the observer instrument, including its wavelength range, spectral slit function, and sampling spectral resolution. $L_{\text {meas }}$ at each wavelength $j$ is

$$
L_{\text {meas }}\left(\lambda_{j}\right)=\int_{-\infty}^{\infty}\left[L^{\circ}(\lambda)+L^{*}(\lambda)\right] f_{\lambda_{j}}\left(\lambda-\lambda_{j}\right) d \lambda,
$$

where $L^{*}$ is the integrated radiance scattered into the instrument field of view (FOV) and $f_{\lambda_{j}}\left(\lambda-\lambda_{j}\right)$ is the instrument line shape function (the $\lambda_{j}$ dependence of $f$ results from the fact that the instrument line shape can vary with wavelength). It should be noted that there is no instrument that measures only the direct solar irradiance. All measurements include light that is scattered into the finite instrument FOV by Rayleigh (molecular) and Mie (aerosol) processes. However, with a sufficiently small instrument FOV, most of the scattered radiation field can be rejected, and $L_{\text {meas }}$ is dominated by $L^{\circ}$ :

$L_{\text {meas }}\left(\lambda_{j}\right) \approx \int_{-\infty}^{\infty} L^{\circ}(\lambda) f_{\lambda_{j}}\left(\lambda-\lambda_{j}\right) d \lambda$.

The present analysis will focus on the approximation Eq. (4). A careful knowledge of the instrument characteristics is essential for the accurate retrieval of composition from irradiance measurements.

\subsection{Retrieval techniques}

Although early work in the retrieval of atmospheric composition from differential transmission inferred optical depth based on comparisons of pairs of wavelengths corresponding to relative maxima and minima in absorption (e.g., Dobson, 1957), moderate- and high-resolution spectrometers provide more complete spectral information, allowing multiple species to be simultaneously measured with high accuracy and precision.

An effective technique commonly employed today for the retrieval of atmospheric composition from spectral flux measurements is differential optical absorption spectroscopy (DOAS) (e.g., Noxon, 1975; Platt, 1994, and references therein). DOAS extracts information from relatively narrow spectral absorption features after broad features, such as from Rayleigh and aerosol extinction, have been removed. The "differential" spectrum is obtained by first dividing the measured flux spectrum by a reference spectrum with none (or 
at most much less) of the species of interest present, which reduces spectral interferences (e.g., Fraunhofer lines in the solar spectrum). The resultant spectrum is therefore composed of narrow absorption features (e.g., due to ozone) superimposed on a slowly varying background largely due to Rayleigh and aerosol scattering, which can then be high-pass filtered in wavelength space to isolate the spectral "fingerprints" of the desired species. Differential laboratory absorption spectra are finally fitted to the differential measured spectrum to yield column densities of the atmospheric constituents of interest (for an example, see Roscoe et al., 1994).

The effect of stratospheric aerosol extinction can be quite pronounced in solar LOS spectra at large solar zenith angles (see Fig. 1). Aerosol extinction is to first order a slowly varying function of wavelength. Although DOAS is a powerful technique for retrieving species with narrow spectral features (e.g., $\mathrm{O}_{2} \cdot \mathrm{O}_{2}$, if it were of principal interest, would perhaps be more easily retrieved from its weak absorption using DOAS), a limitation is that information from broad band extinction is lost. In the next section, we describe a multi-species absolute spectral fitting technique that allows us to simultaneously retrieve ozone, AOT, and other species, based on both narrow and broad spectral information.

\subsection{Multi-wavelength/multi-species composition retrieval technique}

We have developed a flexible technique for the simultaneous fitting and retrieval of multiple contributions to the attenuation of the direct solar irradiance, based on the work of Yee et al. (1991). This multi-wavelength/multi-species technique has also recently been applied to the retrieval of ozone from satellite-based stellar occultation measurements (Yee et al., 2002; DeMajistre and Yee, 2002).

The essence of the retrieval technique used in this study is the iterative comparison of a simulated irradiance spectrum with the measured spectral irradiance. In each iteration, fitted parameters (e.g., $\mathrm{LOS} \mathrm{O}_{3}, \mathrm{O}_{2} \cdot \mathrm{O}_{2}$, AOT) are adjusted to minimize the spectral differences, using a standard $\chi^{2}$ minimization non-linear least squares fitting technique. $\chi^{2}$ is defined as

$\chi^{2}=\frac{1}{n} \sum_{j=1}^{n}\left(\frac{L_{\text {meas }}\left(\lambda_{j}\right)-L_{\text {calc }}\left(\lambda_{j}\right)}{\delta\left(\lambda_{j}\right)}\right)^{2}$,

where $L_{\text {calc }}$ is the simulated irradiance and $\delta$ is the measurement uncertainty (standard deviation) at each of $n$ wavelength spectral elements $\lambda_{j}$. Fitted parameters may also include the wavelength dependence of aerosol extinction, which can be simplified over limited wavelength ranges as

$\operatorname{AOT}(\lambda) \propto\left(\frac{\lambda}{\lambda_{0}}\right)^{-\alpha}$,

where AOT is the aerosol optical thickness, $\lambda_{0}$ is a reference wavelength, and $\alpha$ is the Ångström exponent (e.g., Shifrin, 1995).

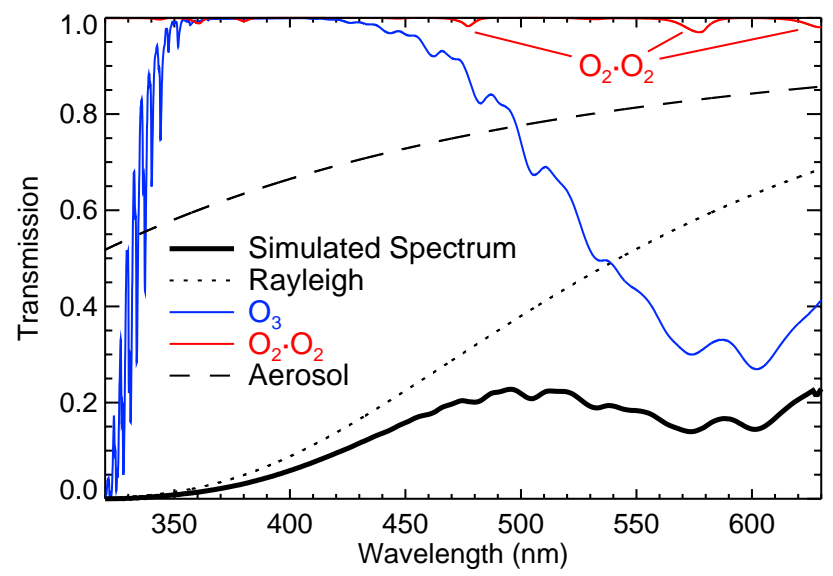

Fig. 1. Simulated line-of-sight transmission spectra. The DIAS spectral transmission was simulated for the following conditions: altitude $=12 \mathrm{~km}, \mathrm{SZA}=90^{\circ}$, temperature $=221 \mathrm{~K}$, column density $=1.4 \times 10^{26} \mathrm{~cm}^{-2}$, column $\mathrm{O}_{3}=2.5 \times 10^{20} \mathrm{~cm}^{-2}$, column $\mathrm{O}_{2} \cdot \mathrm{O}_{2}=2.8 \times 10^{43} \mathrm{O}_{2}$ molecules $\mathrm{cm}^{-5}$, AOT $($ at $400 \mathrm{~nm})=0.41$, and $\alpha^{\text {eff }}=2.1$ (line-of-sight quantities). The transmission spectra of the individual species are also included.

The conditions of the experiment determine which parameters can be reasonably retrieved. In general, our ability to retrieve composition from irradiance measurements is dependent on the quantification of several factors: the characteristics of the instrument, light source (e.g., knowledge of the extraterrestrial flux), molecular parameters (e.g., absorption cross sections), and geophysical parameters (if not retrieved, e.g., atmospheric density and temperature). It is therefore desirable to determine and know a priori each of these factors as well as possible. Effects not accounted for (e.g., cloud extinction) can pose further limitations but can be neglected if their effects are small.

In principle, if the wavelength range of the measured spectrum is large, many different species can be retrieved simultaneously. Even the effective wavelength dependence of the aerosol extinction along the LOS path, $\alpha$ eff , can be independently retrieved with a sufficiently long wavelength "lever arm." When the spectral range is limited (either by the instrument spectral coverage or because of the disappearance of the UV signal at large SZAs), however, the short lever arm can mean that it is difficult to distinguish multiple contributions to the extinction that manifest themselves as smoothly varying functions of wavelength, such as Rayleigh scattering and AOT (one appears to be a DC offset of the other), and it becomes necessary to constrain one of them.

The specific implementation of the retrieval technique to SOLVE II DIAS measurements is described in Sect. 3.2. 
Table 1. DC-8 flight dates and time ranges of DIAS solar irradiance spectra during SOLVE II.

\begin{tabular}{crrc}
\hline Date & Start time $^{2}$ & Stop time $^{2}$ & No. of spectra \\
\hline 12 Jan. 2003 & $10: 09: 14$ & $12: 01: 44$ & 101 \\
14 Jan. 2003 & $09: 47: 44$ & $12: 15: 44$ & 126 \\
16 Jan. 2003 & $09: 46: 44$ & $11: 22: 14$ & 98 \\
19 Jan. 2003 & $08: 34: 14$ & $13: 42: 44$ & 274 \\
21 Jan. 2003 & $14: 36: 44$ & $17: 05: 44$ & 294 \\
24 Jan. 2003 & $09: 49: 14$ & $11: 59: 44$ & 120 \\
26 Jan. 2003 & $11: 50: 44$ & $13: 46: 44$ & 179 \\
29 Jan. 2003 & $10: 16: 44$ & $11: 43: 44$ & 92 \\
31 Jan. 2003 & $09: 37: 44$ & $10: 39: 14$ & 71 \\
02 Feb. 2003 & $09: 59: 14$ & $12: 47: 44$ & 206 \\
06 Feb. 2003 & $14: 43: 14$ & $16: 18: 14$ & 181
\end{tabular}

1 All dates in dd/mm/yyyy format.

2 All times in hh:mm:ss UT format.

\section{SOLVE II experiment description}

\subsection{Direct beam Irradiance Atmospheric Spectrometer}

\subsubsection{Instrument description}

The NCAR Direct beam Irradiance Atmospheric Spectrometer instrument is a scanning spectroradiometer designed to determine the direct solar UV and visible irradiance from 290 to $630 \mathrm{~nm}$ with roughly 1-nm resolution (resolution comparable to SAGE III). The instrument comprises three subsystems: a narrow-field-of-view optical collector, a microprocessor-controlled 2-axis gimbal pointing system, and a scanning double monochromator detection system, based on an instrument used by Shetter and Müller (1999) for spectral actinic flux measurements from aircraft.

The optical collector was set up to view the Sun through a fused silica optical window mounted on the left side of the DC-8 aircraft. Although in principle the entire solar disk could be sampled with a $\sim 0.5^{\circ}$ field of view, a $3.6^{\circ}$ DIAS FOV allows for some inaccuracy and/or short time lags in the response of the pointing system, without inducing significant errors in the measurements. Its narrow FOV accepts the direct solar beam while excluding almost all of the atmospherically scattered radiation ( $L^{*}$ in Eq. 3 ). Under most circumstances, the contribution from atmospheric scattering is negligible; the circumstances under which this assumption breaks down are discussed in Sect. 3.2. The collection optic is mounted to the pointing system at the center of rotation and is optically connected to the detection system with a flexible UV fiber optic bundle. The solar tracking system contains a 2-axis gimbal, a position sensing system, and an embedded controller system (position resolution of $0.004^{\circ}$ ). The double monochromator detection system employs a fused silica fiber optic bundle, an f/\#-matching optic, an $\frac{1}{8}$-m scanning double monochromator, a UV-sensitive ultra-low dark current bialkali photomultiplier, a custom 4-channel electrometer/amplifier, and a rack-mounted data acquisition and control system.

The FWHM of the double monochromator is $\sim 1.0 \mathrm{~nm}$ using $2400-\mathrm{g} / \mathrm{mm}$ gratings and $600-\mu \mathrm{m}$ entrance and exit slits, which produces a symmetrical triangular slit function. The combination of the photomultiplier tube detector sensitivity and grating efficiency applied to the solar spectrum results in detectable data between 290 and $\sim 630 \mathrm{~nm}$, which can be scanned in approximately $30 \mathrm{~s}$. The double monochromator used has a stray light rejection of $>10^{9}$ (manufacturer specification). The instrument was calibrated for wavelengthdependent spectral sensitivity and wavelength registration in a laboratory calibration system at NCAR using NISTtraceable irradiance standards and mercury line sources. Calibrations were also performed in the field through the aircraft optical window before and after each flight using a quartz-tungsten-halogen lamp mounted in a calibration optical bench to monitor the instrument sensitivity drift.

For the absolute calibration of the irradiance, the largest uncertainty arises from the calibration lamp certification (4.0\% in the UV-B range and $3.0 \%$ in the UV-A/visible range). We estimate the precision of the calibration measurements to be approximately $2.0 \%$.

\subsubsection{Measurements}

The DIAS instrument produced solar irradiance spectra during 11 SOLVE II flights. Table 1 summarizes the DIAS flights and the number of solar spectra available for retrieval.

A simulated DIAS transmission spectrum is shown in Fig. 1, for an arbitrary set of SOLVE II conditions. The transmission spectra for the principal sources of atmospheric extinction are also included for comparison. DIAS data have sufficient precision to retrieve even $\mathrm{O}_{2} \cdot \mathrm{O}_{2}$ (at large SZAs), despite its small overall contribution to the total extinction. Absorption features from $\mathrm{NO}_{2}, \mathrm{BrO}$, and $\mathrm{OClO}$, however, were too small $(<1 \%)$ to discern under these conditions.

\subsection{Retrieval implementation}

The DIAS spectral simulator (for $L_{\mathrm{calc}}$ ) was based on the extraterrestrial solar irradiance, temperature-dependent absorption cross sections, temperature, LOS column amounts of total density (for Rayleigh scattering), $\mathrm{O}_{3}$, and $\mathrm{O}_{2} \cdot \mathrm{O}_{2}$, AOT, $\alpha^{\mathrm{eff}}$, and the DIAS instrument spectral line shape, as shown in Fig. 2. The flow chart shows schematically how our retrieval was typically applied during SOLVE II to DIAS solar irradiance measurements for the retrieval of $N_{\mathrm{O}_{3}}, N_{\mathrm{O}_{2} \cdot \mathrm{O}_{2}}$,


the retrieval).

The DIAS field of view is generally dominated by the direct solar irradiance in the visible and near-UV. As the Sun nears the horizon, however, atmospheric scattering into the 


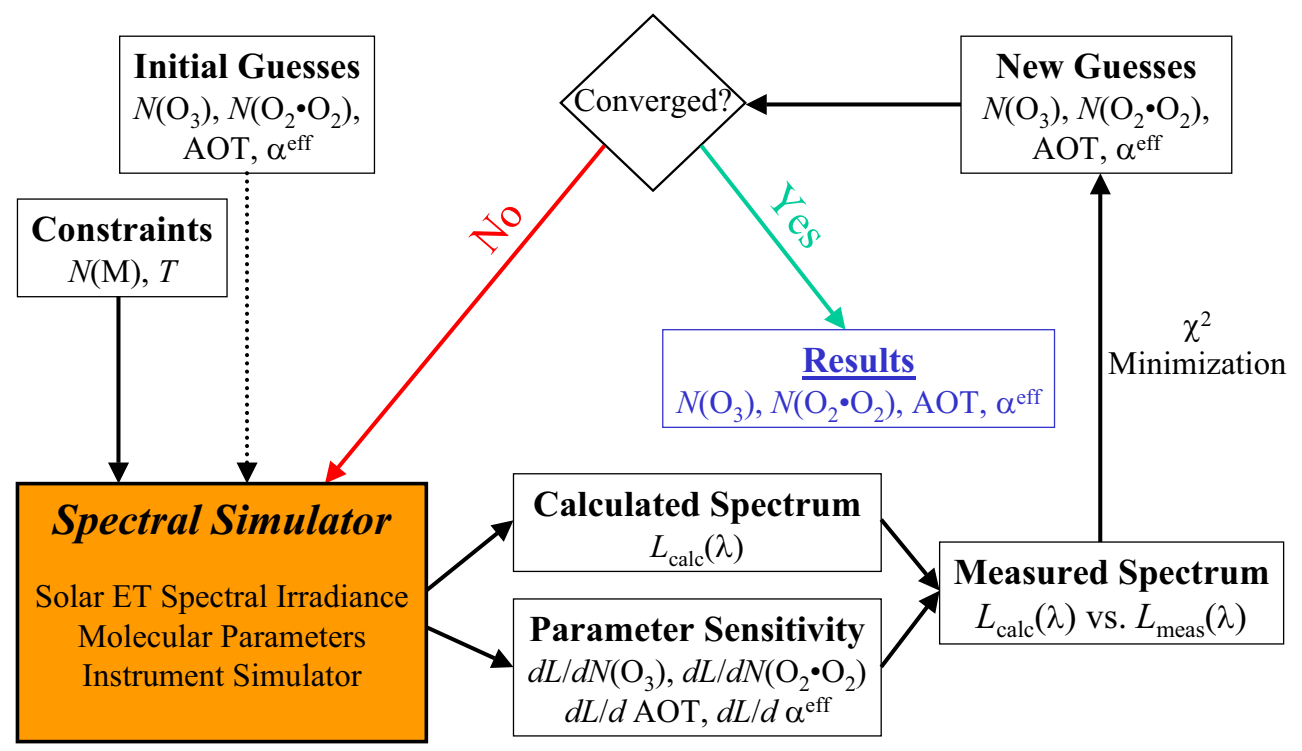

Fig. 2. Flow chart showing the algorithmic steps taken to retrieve line-of-sight composition. In this particular case, $\mathrm{O}_{3}, \mathrm{O}_{2} \cdot \mathrm{O}_{2}$, and the aerosol optical thickness and effective Ångström exponent $\alpha^{\text {eff }}$ are the free parameters to be fit. The process begins with spectral simulation, based on initial guesses (which need not be accurate) of the quantities to be retrieved, geophysical constraints, and instrument spectral simulation. The calculated spectrum is compared with the actual measured spectrum, and the free parameters are adjusted. Standard $\chi^{2}$ minimization of the non-linear least squares fit is used to achieve convergence of the retrieval parameters. $N($ ) denote LOS column abundances of the indicated species, including total density $N(\mathrm{M}) ; T$ is the temperature; and $L_{\text {calc }}$ and $L$ meas are the calculated and measured spectral irradiance, respectively.

instrument ( $L^{*}$ in Eq. 3 ) becomes increasingly significant at UV wavelengths, at the same time ozone absorption removes more and more of the direct solar signal. Radiative transfer modeling, using the MODTRAN3 model (Berk et al., 1989), suggests that atmospheric scattering into the DIAS $3.6^{\circ} \mathrm{FOV}$ is comparable to or greater than the direct solar component at wavelengths shorter than $320 \mathrm{~nm}$ at $90^{\circ} \mathrm{SZA}$, at DC-8 altitudes. We therefore elected to only use wavelengths longer than $320 \mathrm{~nm}$ in this analysis, and we do not model enhancement to the DIAS irradiance measurements due to atmospheric scattering into the instrument field of view.

The wavelength range for the retrieval, $320-630 \mathrm{~nm}$, was not sufficient to reliably separate Rayleigh extinction and $\alpha^{\text {eff }}$, so it was necessary to constrain one of them. We chose to constrain the total density along the LOS path (which determines the Rayleigh extinction), which can be readily and accurately modeled using meteorological analyses (e.g., UKMO). The contribution of Rayleigh extinction to the total irradiance attenuation, however, is significant (see Fig. 1). It is important to note that small errors in the density can lead to increased errors in the retrieval of lesser absorbers (e.g., AOT and $\alpha^{\text {eff }}$, see Sect. 4.5.2). It is therefore critical that the calculated SZA and refracted light path be accurate. We note that the selection of the initial guesses for the free parameters can be somewhat arbitrary, since the algorithm is relatively insensitive to the initial guesses, and convergence can be attained usually within three iterations.
At SZAs less than about $87^{\circ}$, most of the ozone information in the retrieval comes from the Huggins bands in the UV; at larger SZAs, the Chappuis bands become relatively more important and dominate at $\mathrm{SZA}>90^{\circ}$, as $\mathrm{UV}$ transmission becomes negligible. The retrieval technique automatically weights contributions from these two regions by their measurement precision.

\subsubsection{Molecular and geophysical data used in the retrieval}

The specific molecular and geophysical data used in the retrieval are listed in Table 2. Since the vertical structure of the atmosphere was relatively isothermal in the vicinity of the DC-8 during SOLVE II, and since the greatest contribution to the ozone slant column came from the lower stratosphere, often within a few kilometers of the aircraft altitude, the in situ aircraft temperature was used for the $\mathrm{O}_{3}$ and $\mathrm{O}_{2} \cdot \mathrm{O}_{2}$ cross section calculations. For the column density constraint, we first interpolated the daily UKMO reanalysis (Swinbank and O'Neill, 1994) meteorological density fields (calculated from temperature fields gridded at $3.75^{\circ}$ longitude $\times 2.5^{\circ}$ latitude at 18 pressure levels from 1000 to $0.4 \mathrm{mb}$ ) to the aircraft positions along the flight track for each day. The refracted, wavelength-dependent line-of-sight path of the solar beam was then computed for all DIAS wavelengths (see Yee et al., 2002; DeMajistre and Yee, 2002; Vervack et al., 2002). The atmosphere was assumed to be spatially (horizontally) 
Table 2. Retrieval extraterrestrial solar irradiance, molecular parameters, and other geophysical input data.

\begin{tabular}{ll}
\hline Data & Source \\
\hline $\begin{array}{l}\text { ET solar irradiance: } \\
320-420 \mathrm{~nm}\end{array}$ & ATLAS (Kaye and Miller, 1996; Woods et al., 1996) \\
$420-630 \mathrm{~nm}$ & MODTRAN3 (Berk et al., 1989) \\
\hline Cross sections: & \\
Rayleigh scattering & Bodhaine et al. (1999) ${ }^{2}$ \\
$\mathrm{O}_{3}$ & MODTRAN3 (Berk et al., 1989) \\
$\mathrm{O}_{2} \cdot \mathrm{O}_{2}, \lambda<460 \mathrm{~nm}$ & Greenblatt et al. (1990) \\
$\mathrm{O}_{2} \cdot \mathrm{O}_{2}, \lambda \geq 460 \mathrm{~nm}$ & Newnham and Ballard (1998) \\
\hline Geophysical constraints: $^{4}$ & \\
Column density & UKMO reanalysis (Swinbank and O'Neill, 1994) \\
Temperature & in situ \\
\hline
\end{tabular}

1 Shifted to air wavelengths.

${ }^{2}$ Using Bodhaine et al.'s "best-fit" Eq. (29), which is reported as being accurate to better than $0.01 \%$ over $250-850 \mathrm{~nm}$.

3 Temperature-dependent cross sections; derived from Bass and Paur (1985) at UV wavelengths and from a measurement compilation by Shettle and Anderson (1995) in the visible.

4 Cross sections measured at $223 \mathrm{~K}$ used for temperatures less than $223 \mathrm{~K}$; cross sections at higher temperatures linearly interpolated between determinations at 223 and $283 \mathrm{~K}$. Data were smoothed to reduce noise in the original measurements.

homogeneous along the LOS at each point along the flight track, and the refracted path was used to interpolate the vertical profile to yield LOS total density. The wavelengthdependent total column density was then used to calculate Rayleigh extinction and constrain the retrieval.

\subsubsection{Sample retrieval and comparison with measured spectra}

Several fitted spectra from the 6 February 2003 flight in Fig. 3 show the goodness of the retrieval fit. The transmission spectra at five SZAs are shown, ranging from $78^{\circ}$ to $92^{\circ}$. The fit is excellent, even in the near-UV and when the Sun was barely above the horizon, demonstrating the quality of the DIAS irradiance measurements and the robustness of the fits. At $92^{\circ}$, the deviations at the shortest wavelengths are possibly due to a combination of factors, including imprecise wavelength registration with the temperature-dependent ozone cross sections, signal-to-noise limitations, and atmospheric scattering into the DIAS field of view (see Sect. 4.5.2 for further discussion of retrieval accuracy). The retrieval technique is weighted by the measurement precision (i.e., noise) in the formulation of $\chi^{2}$ (see Eq. 5); thus the signal from the diminished-UV region (and its relatively larger error) contributes less to the fit at large SZAs, and the retrieved parameters are determined by the visible part of the spectrum.

\section{Results}

In this section we compare the retrieval results from two flights, 19 January 2003 and 6 February 2003, with forwardmodeling calculations and then present statistical results from six science flights, including intercomparison with AATS-14. Because of the wavelength-dependent effects of refraction, the true slant (LOS) column quantities are functions of wavelength (see Sect. 2.1), most significantly at the largest SZAs. Therefore, the retrieved $\mathrm{LOS}_{3}$ and $\mathrm{O}_{2} \cdot \mathrm{O}_{2}$ presented are arbitrarily referenced to the $320-\mathrm{nm}$ refracted light path (in the ozone Huggins bands). The difference between SOLVE II retrieved $N_{\mathrm{O}_{3}}$ referenced to $320 \mathrm{~nm}$ and $600 \mathrm{~nm}$ is small, however, less than $1 \%$. Although we retrieved the AOT as a function of wavelength, the AOT values presented in this paper are referenced to $400 \mathrm{~nm}$.

\subsection{Forward-modeling of line-of-sight $\mathrm{O}_{3}$ and $\mathrm{O}_{2} \cdot \mathrm{O}_{2}$ for comparison}

We forward-modeled the LOS $\mathrm{O}_{2} \cdot \mathrm{O}_{2}$ column by simply integrating $\left(n_{\mathrm{O}_{2}}\right)^{2}$ from the density profile used to constrain the Rayleigh scattering in the retrieval (see Sect. 3.2.1). For ozone, we used primarily the data collected by other instruments on the DC-8. Vertical ozone profiles were constructed along the flight track, similar to density. We started with profiles measured by the Differential Absorption Lidar (DIAL) instrument (Browell et al., 1998; Grant et al., 1998), which provided ozone profiles from the lower troposphere to about $25 \mathrm{~km}$. Since the lidar instrument does not report 


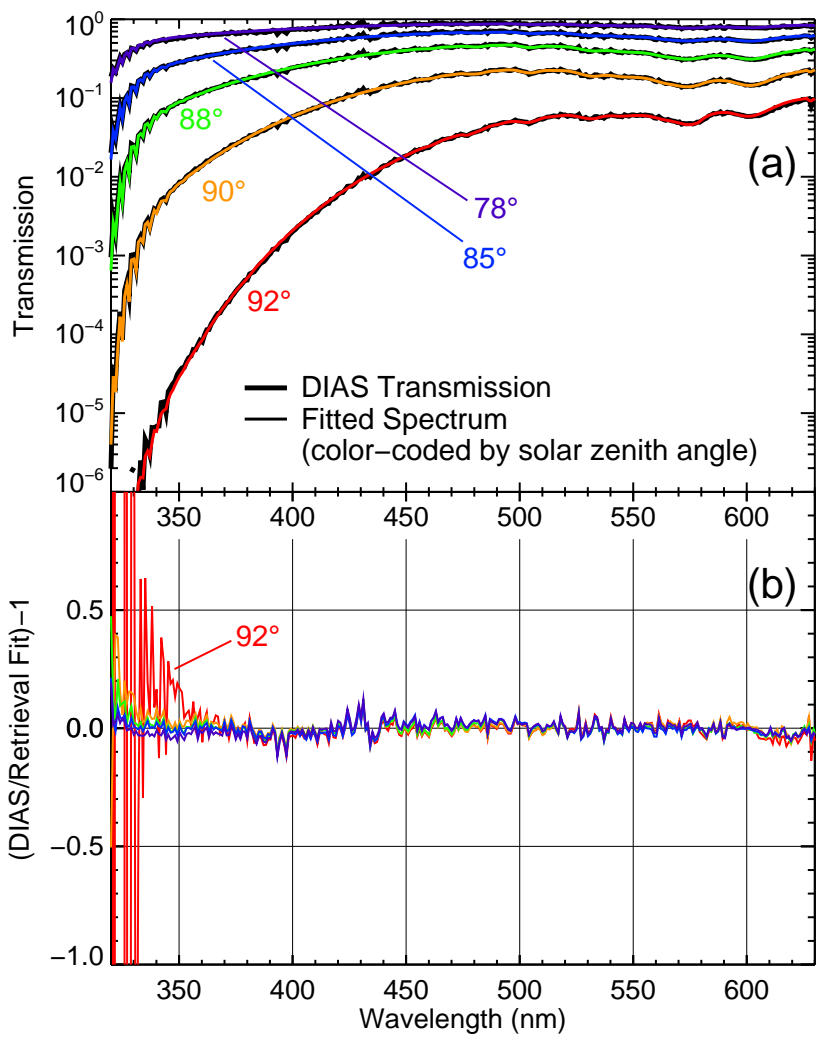

Fig. 3. Goodness of fits. (a) DIAS transmission spectra at five SZAs, $78^{\circ}-92^{\circ}$, from 6 February 2003 DC-8 flight, with fitted spectra overlaid. (b) Relative transmission difference, (DIAS/fitted spectra) -1 , with the same SZA color-coding as (a).

ozone within about $1 \mathrm{~km}$ of the DC- 8 altitude, we vertically interpolated the profile to the in situ ozone measurements made by the chemiluminescent "FASTOZ" instrument (http: //cloud1.arc.nasa.gov/solveII/instrument_files/O3.pdf), similar to that used by Swartz (2002) to constrain ozone profiles during the first SOLVE mission. Temporal gaps were interpolated. Above the lidar profiles, we added the closest solar occultation profile measured by the Polar Ozone and Aerosol Measurement (POAM) III (Lumpe et al., 2002), from $\sim 25$ to $60 \mathrm{~km}$. Above $60 \mathrm{~km}$ (and also very close to the surface, below the lidar profiles), the MODTRAN (Berk et al., 1989) sub-Arctic winter ozone profile was used, but the contribution at this altitude is insignificant. These ozone profiles were integrated as was density to yield wavelength-dependent column ozone.

\subsection{January 2003 DC-8 flight}

The 19 January 2003 DC-8 flight was chosen for a case study because it was located in the heart of the SOLVE II study region over Scandinavia, and it was designed to coincide with both SAGE III and POAM III occultations. It provided many DIAS spectra at a range of SZAs. The flight also scanned
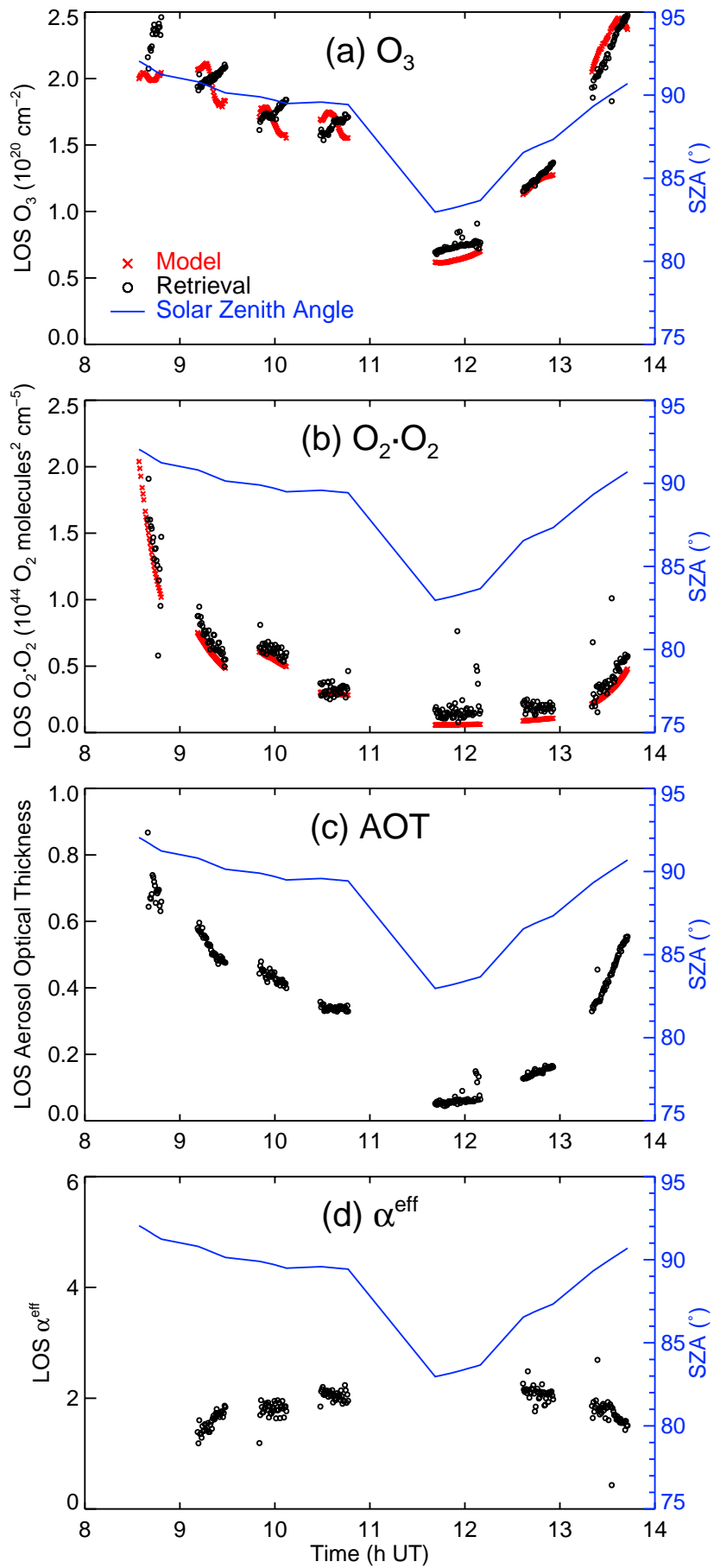

Fig. 4. Retrieved line-of-sight (slant) column (a) $\mathrm{O}_{3}$, (b) $\mathrm{O}_{2} \cdot \mathrm{O}_{2}$, (c) aerosol optical thickness at $400 \mathrm{~nm}$, and (d) effective Ångström exponent $\alpha^{\text {eff }}$, for the 19 January 2003 DC-8 flight. Modeled $\mathrm{O}_{3}$ and $\mathrm{O}_{2} \cdot \mathrm{O}_{2}$ are also shown for comparison. Each panel also includes the SZA at the aircraft along the flight track (in blue).

ozone and aerosols through the polar vortex boundary region. Figure 4 shows the retrieved LOS quantities from the 19 January 2003 flight, along with forward-modeled $\mathrm{O}_{3}$ and 

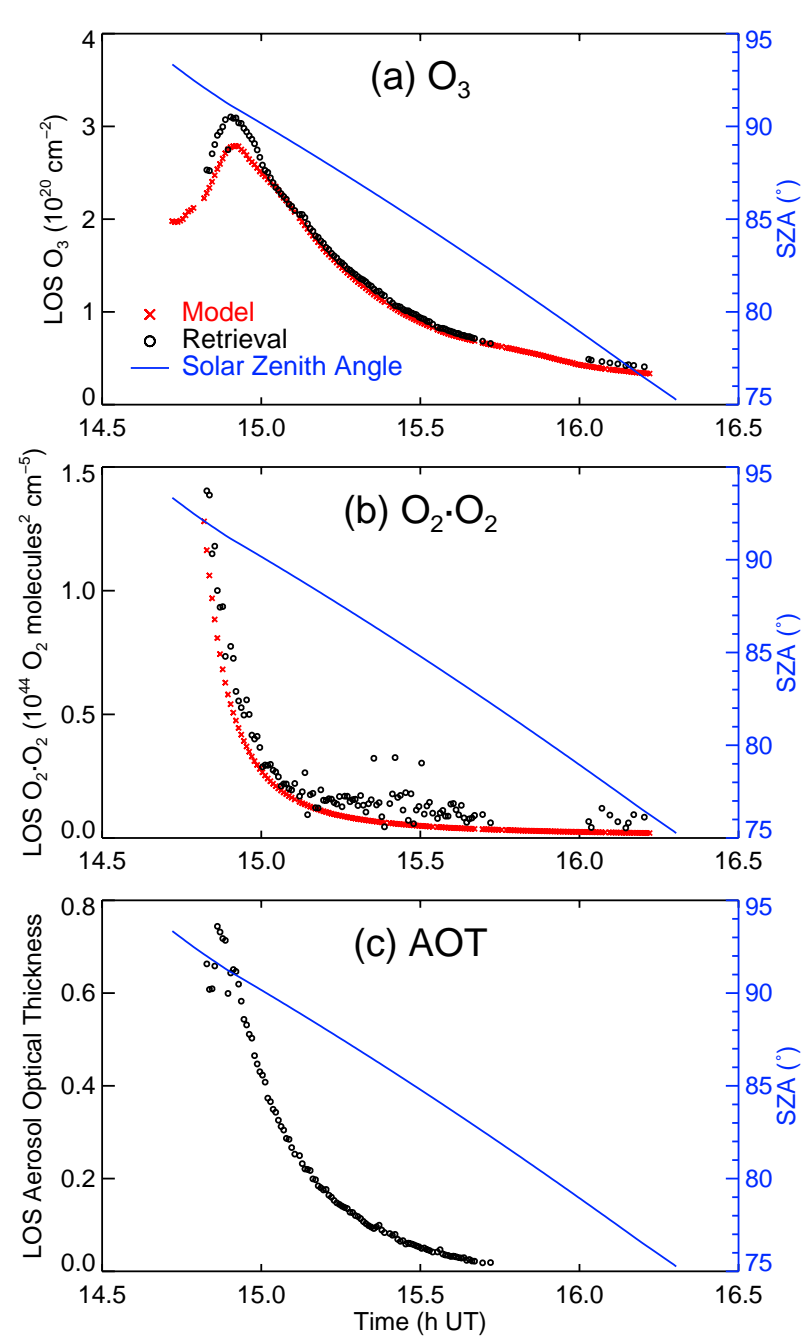

Fig. 5. Same as Figs. 4a-c, except for the 6 February 2003 flight.

$\mathrm{O}_{2} \cdot \mathrm{O}_{2}$. The strong SZA-dependence of the slant columns is evident. (No attempt is made in this paper to infer vertical column amounts, but we rather focus entirely on the measured slant column. Inference of vertical columns requires additional assumptions and leads to more uncertainty.) Comparisons of retrieved ozone (and AOT) with AATS-14 are in excellent agreement and track very closely (not shown; see statistics in Sect. 4.4; Livingston et al., 2005; Russell et al., 2004). The model-retrieval ozone agreement is in general quite good. It is important to note that, just like LOS satellite retrievals, the forward model assumes spatial (horizontal) homogeneity, which can be a significant source of error, especially in the vicinity of the vortex edge region, where there are marked ozone gradients. The repeating discrepancies in the first half of the flight are likely due to inhomogeneities. AOT at the smallest SZAs gets relatively thin, and thus $\alpha$ eff becomes quite uncertain. At large SZAs, as the LOS passes through the troposphere, attenuation of the UV shortens the wavelength lever arm, also making $\alpha$ eff difficult to retrieve. At intermediate SZAs, however, the $\alpha^{\text {eff }}$ is routinely close to 2.

\subsection{February 2003 DC-8 flight}

The results for the 6 February 2003 flight are shown in Fig. 5. This flight was a transit from Kiruna, Sweden to NASA Dryden Flight Research Center in California, USA. DIAS data are available after sunrise, over the western United States. The flight covers a continuous range of SZA and is far from the Arctic, in contrast to the 19 January 2003 flight. The slant column ozone peaks at $90^{\circ}$. The agreement between the retrieved and modeled ozone is good, especially at SZAs smaller than $88^{\circ}$. Closer to sunrise, there is a more notable discrepancy. The strong SZA dependence in $\mathrm{O}_{2} \cdot \mathrm{O}_{2}$ is also apparent, which is in good agreement with the forward model. The AOT is very small at $80^{\circ} \mathrm{SZA}$, and $\alpha \mathrm{eff}_{\text {was dif- }}$ ficult to retrieve for most of the flight, due to the small slant AOT.

\subsection{SOLVE II intercomparison statistics}

The DIAS LOS $\mathrm{O}_{3}$ retrieval results from six flights, 19 January 2003-2 February 2003, are shown in Fig. 6 in comparison with both forward-modeled calculations and retrievals made by AATS-14. The model has a $-9.6 \%$ mean relative difference as compared to the DIAS measurements, with a root-mean-square (rms) relative difference of $12.5 \%$. DIASmodel discrepancies may be due to errors in the meteorological analyses or ozone inhomogeneity not captured by the vertical profiles used in the forward model. We have found that a three-dimensional forward model that does not rely on the assumption of spatial homogeneity, using $\mathrm{O}_{3}$-potential vorticity proxy-mapped 3-D fields, produces calculations with less bias and rms noise (Y05-ms). The comparison with AATS-14 is excellent, with a $-1.6 \%$ mean relative difference and $2.1 \%$ rms relative difference (see also Livingston et al., 2005). Similar analysis of the retrieved AOT at $400 \mathrm{~nm}$ has found a DIAS-AATS mean difference of $-2.3 \%$ (rms $7.7 \%$ ) (Russell et al., 2004).

4.5 Error assessment of the DIAS retrieval during SOLVE II

\subsubsection{Retrieval precision}

The retrieval precision, based on DIAS measurement photon statistics, was on the order of $1 \%$ for $\mathrm{O}_{3}, 60-5 \%$ for $\mathrm{O}_{2} \cdot \mathrm{O}_{2}$, $4-1 \%$ for AOT, and $4-15 \%$ for $\alpha$ eff, for the $83^{\circ}-91^{\circ}$ range of SZAs found in the 19 January 2003 flight, respectively.

\subsubsection{Retrieval accuracy}

There are several sources of systematic error in the retrieval of column composition from direct solar irradiance 
measurements that need to be considered, relating to the DIAS instrument and other geophysical parameters and constraints. These will be addressed in turn as follows. In some cases, we determined the retrieval's sensitivity to various errors by perturbing its input data accordingly.

A source of light not attributed to the direct solar irradiance is atmospheric scattering into the DIAS field of view ( $L^{*}$ in Eq. 3). Finite scattering contamination in the UV at large SZAs could impact the retrieval by effectively increasing the apparent direct transmission. This would reduce the apparent AOT at the short-wavelength end of the spectrum. Modeling calculations of the DIAS $3.6^{\circ}$ FOV suggest that limiting the retrieval to wavelengths longer than $320 \mathrm{~nm}$ (as in this analysis) renders the influence generally negligible (see Sect. 3.2). The effect of minor atmospheric scattering contamination at wavelengths greater than $320 \mathrm{~nm}$ has also been minimized since the retrieval weighting is already small under these low-signal-to-noise conditions. This small effect could be reduced by further limiting the wavelength range of the retrieval at very large SZAs.

Stray light rejection, especially in the near-UV, where the solar radiation is changing by orders of magnitude over a short wavelength range, coupled with a photomultiplier tube that is more sensitive to visible photons, is a factor that must be considered with all UV/visible spectrometers. The DIAS instrument employs a double-pass monochromator with a manufacturer-specified stray light rejection of $>10^{9}$, to significantly reduce instrument "red leak". DIAS measurement statistics were not precise enough to completely verify this level of rejection, but statistically zero signal was observed below the atmospheric UV cutoff of $\sim 294 \mathrm{~nm}$, suggesting that red leak was negligible. In any event, limiting the analysis to wavelengths longer than $320 \mathrm{~nm}$, as discussed above, would rule out any potential contamination of the UV signal under low-light conditions, such as at large SZAs. The uncertainty in the absolute radiometric calibration of the instrument is less than $4 \%$, which corresponds to a roughly $1 \%$ effect on the ozone retrieval, since the technique fits ozone's spectral features. Wavelength registration errors (air wavelengths were used for this analysis), which can produce mismatches of sharp spectral features in the extraterrestrial flux and cross sections, leading to fitting errors, were minimized by calibration with a mercury emission line source. Finally, the DIAS spectral simulator relies on knowledge of the instrument slit function, which also contains finite error. The slit function was experimentally determined in the laboratory with a spectral sampling resolution of $0.1 \mathrm{~nm}$.

The retrieval depends on the measurement accuracy of the extraterrestrial flux and absorption cross sections of $\mathrm{O}_{3}$ and $\mathrm{O}_{2} \cdot \mathrm{O}_{2}$, with their temperature dependencies. The ATLAS extraterrestrial flux is now widely preferred in the literature (Gröbner and Kerr, 2001; Bais et al., 2003) and has been adopted here as the basis for comparison to infer atmospheric transmission. The ozone cross sections are based on the in situ aircraft temperature. Differences with the effective

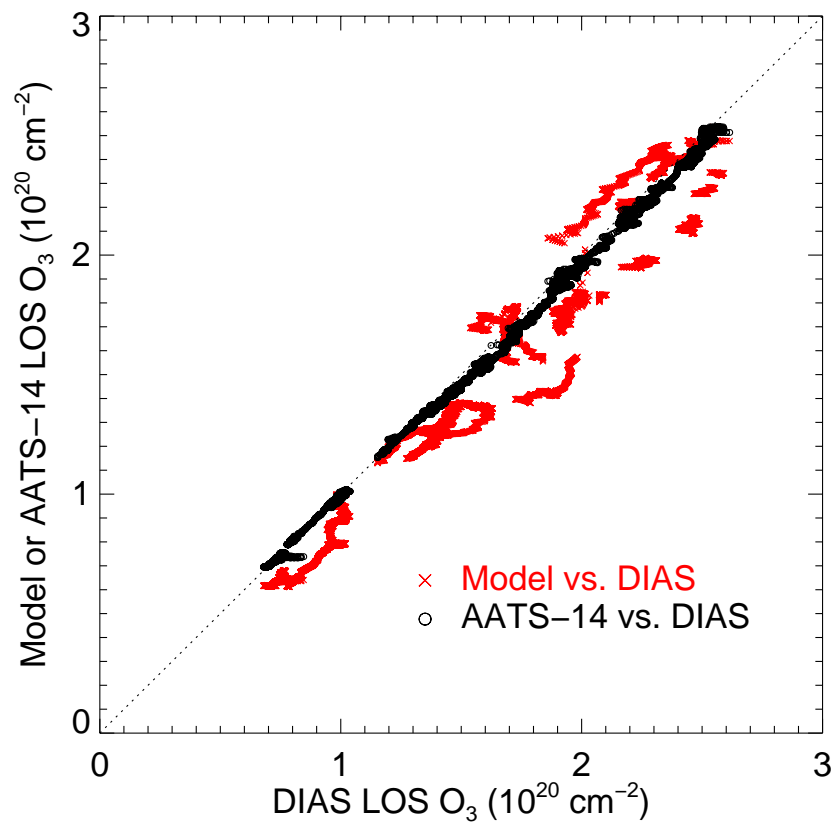

Fig. 6. Intercomparison of forward-modeled and AATS-14 retrieved LOS ozone with DIAS retrieved ozone for six flights, 19 January 2003-2 February 2003.

LOS cross sections will cause an estimated error of less than $5 \%$ for SOLVE II conditions. Similarly, the temperaturedependent Newnham and Ballard (1998) $\mathrm{O}_{2} \cdot \mathrm{O}_{2}$ cross sections were used, which have been preferred in recent work (see Acarreta et al., 2004).

The retrieval accuracy also depends on the Rayleigh constraint. We used the Rayleigh scattering cross section formulation of Bodhaine et al. (1999), which is reported as being accurate to better than $0.01 \%$ over $250-850 \mathrm{~nm}$. The Rayleigh constraint, however, depends on the LOS density, which had to be calculated. The retrieval for the 19 January 2003 flight was run with the density constraint scaled by $\pm 1 \%$ and $\pm 5 \%$. The results relative to the unscaled case are shown in Fig. 7. It is important to note the normal case with unscaled density contains error itself, and it is thus not considered a perfect reference. The results show that for ozone, a $1 \%$ change in the density results in a $0.5 \%$ change in retrieved ozone near $90^{\circ} \sim \mathrm{SZA}$. The change in $\mathrm{O}_{2} \cdot \mathrm{O}_{2}$ is comparable, with the largest changes at the largest and smallest SZAs of the flight (i.e., $92^{\circ}$ and $83^{\circ}$ ). AOT exhibits a uniform change approximately 10 times the fractional change in density. In other words, a $1 \%$ change in the density constraint results in a $10 \%$ change in the retrieved AOT. The $\alpha$ eff is also very sensitive to the density constraint. In order to accurately retrieve aerosol optical properties, the density must be accurately known. We integrated the refracted path to the Sun through same-day UKMO meteorological analyses to determine the LOS density. The slant column density is heavily weighted close to the aircraft; the measured in situ density on 

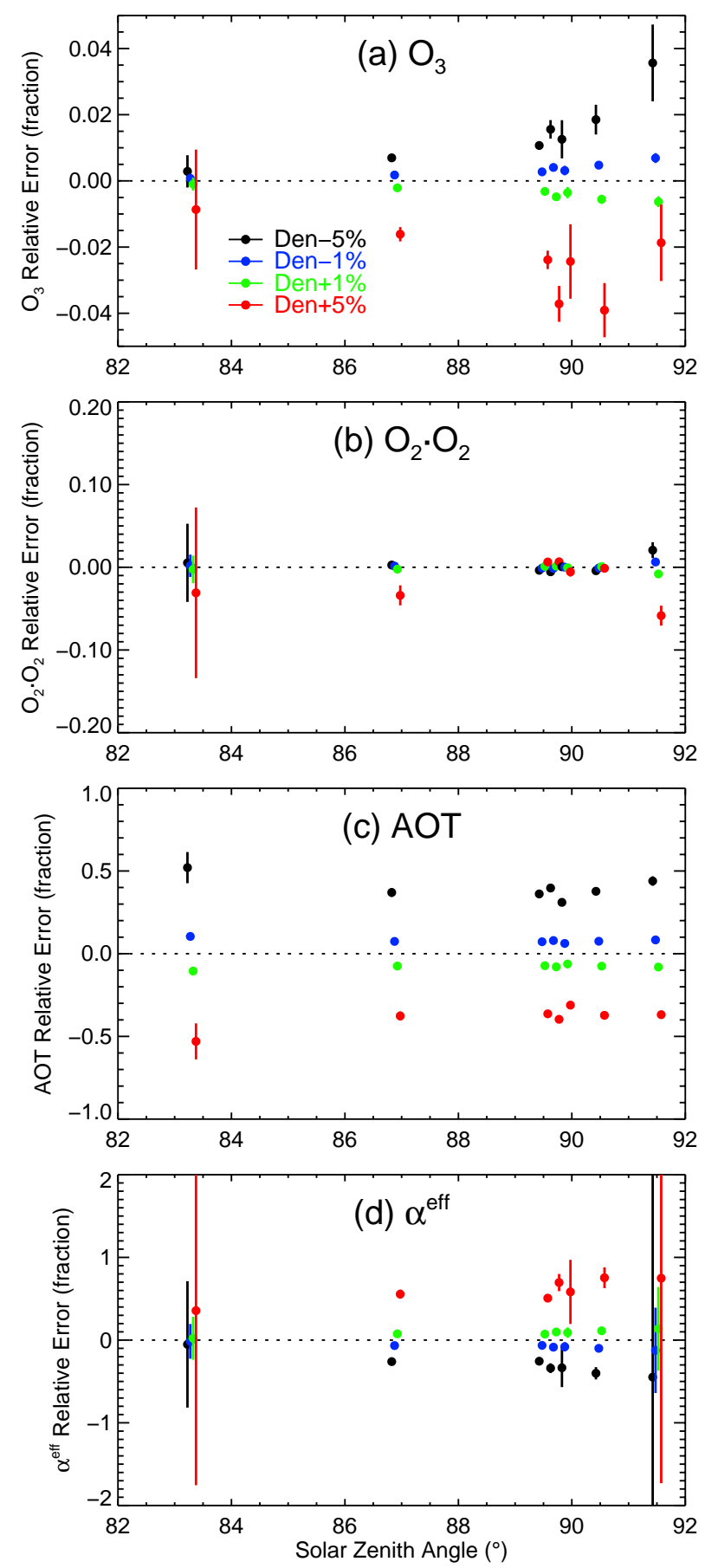

Fig. 7. Relative retrieval sensitivity to changes in the line-of-sight column density constraint for (a) $\mathrm{O}_{3}$, (b) $\mathrm{O}_{2} \cdot \mathrm{O}_{2}$, (c) AOT at $400 \mathrm{~nm}$, and (d) $\alpha$ eff. Four additional retrievals were performed for the 19 January 2003 flight, with the density constraint perturbed by $\pm 1 \%$ and $\pm 5 \%$, and the retrieved quantities are compared with the nominal case (data from Fig. 4), binned by the mean SZA of each of the seven fight legs. Solid dots represent the mean effect in each leg, with vertical whiskers showing the $1-\sigma$ standard deviation (staggered horizontally for clarity). the DC-8 differed from the meteorological analyses by less than $0.3 \%$ on average, suggesting only small inaccuracies in the LOS density and retrieved quantities.

In order to correctly integrate the column density, the SZA and refracted light path must be well known. We have found that when the Sun is near the horizon, small errors in SZA $\left(<0.1^{\circ}\right)$ can result in density errors of a few percent, which could in turn produce AOT errors on the order of several tens of percent. Our calculation of SZA is estimated to be better than $0.005^{\circ}$.

\subsubsection{Special considerations}

A final consideration is that of the geophysical variance of the atmosphere itself along the line of sight, which is an issue that affects the interpretation of all occultation, limbviewing, and nadir satellite measurements. The density constraint and the forward model comparisons $\left(\mathrm{O}_{3}\right.$ and $\left.\mathrm{O}_{2} \cdot \mathrm{O}_{2}\right)$ assumed spatial homogeneity. In reality, however, the retrieval included horizontal gradients along the LOSs. This is particularly relevant to ozone distributions at high latitudes, where large inhomogeneities are present. There is a pressing need to quantify the effects of spatial inhomogeneity on satellite instrument retrievals as measurement accuracies improve. There is a wealth of aircraft and satellite data collected during SOLVE II, however, that is currently being analyzed in order to better characterize errors associated with the homogeneity assumption (Y05-ms).

\section{Summary and conclusions}

We have developed a flexible technique for the independent, simultaneous retrieval of $\mathrm{O}_{3}, \mathrm{O}_{2} \cdot \mathrm{O}_{2}$, AOT, and effective AOT wavelength dependence, $\alpha$ eff, from NCAR DIAS direct solar spectral irradiance measurements on-board the NASA DC-8 during SOLVE II. The approach accounts for the wavelengthdependent refractive bending of the solar line of sight and is effective to very large SZAs. The total line-of-sight density has been constrained, based on integration of meteorological analyses, but Rayleigh extinction could also be retrieved in principle from spectra of sufficient wavelength range (wide enough to distinguish the Rayleigh and AOT wavelength dependencies). We find that the retrieval, especially that of aerosol optical properties, is sensitive to the total density constraint, which needs to be known very accurately.

Statistical comparisons of retrieved ozone and AOT for six flights, 19 January 2003-2 February 2003, with AATS-14 retrievals are in good agreement, with mean relative differences of $-1.6 \%$ (rms $2.1 \%$ ) and $-2.3 \%$ ( $\mathrm{rms} 7.7 \%$ ), respectively (see also Livingston et al., 2005; Russell et al., 2004).

Detailed results from the 19 January 2003 and 6 February 2003 flights have been presented, and $\mathrm{LOS}_{3}$ and $\mathrm{O}_{2} \cdot \mathrm{O}_{2}$ are in good agreement with forward-modeling calculations, based on the integration of vertical density and ozone 
profiles, the latter based on DIAL lidar, FASTOZ in situ, and POAM III occultation measurements of ozone. This agreement could be improved if the spatial inhomogeneity of the atmosphere were accounted for. The total LOS total density (and $\mathrm{O}_{2} \cdot \mathrm{O}_{2}$ ) could be determined by integration of the threedimensional meteorological analyses. Similarly, more realistic LOS ozone could be derived from 3-D ozone fields (Y05$\mathrm{ms}$ ), such as those of Randall et al. (2005), which have been shown to accurately capture ozone spatial inhomogeneities.

Acknowledgements. We thank the DC-8 pilots and crew who participated in SOLVE II, as well as the scientific investigators who made the mission possible. Very helpful comments and suggestions by H. Roscoe (British Antarctic Survey) and another, anonymous referee significantly improved the clarity of this paper. This research was supported by NASA Atmospheric Chemistry Modeling and Analysis Program/Upper Atmosphere Research Program grants NAG5-9988, NAG5-11035, and NNG04GH56G, NASA's Solar Occultation Satellite Science Team, and JHU/APL internal funds.

Edited by: K. Carslaw

\section{References}

Acarreta, J. R., De Haan, J. F., and Stammes, P.: Cloud pressure retrieval using the $\mathrm{O}_{2}-\mathrm{O}_{2}$ absorption band at $477 \mathrm{~nm}$, J. Geophys. Res., 109, D05204, doi:10.1029/2003JD003915, 2004.

Bais, A. F., Madronich, S., Crawford, J., Hall, S. R., Mayer, B., van Weele, M., Lenoble, J., Calvert, J. G., Cantrell, C. A., Shetter, R. E., Hofzumahaus, A., Koepke, P., Monks, P. S., Frost, G., McKenzie, R., Krotkov, N., Kylling, A., Swartz, W. H., Lloyd, S. A., Pfister, G., Martin, T. J., Roeth, E. P., Griffioen, E., Ruggaber, A., Krol, M., Kraus, A., Edwards, G. D., Mueller, M., Lefer, B. L., Johnston, P., Schwander, H., Flittner, D., Gardiner, B. G., Barrick, J., and Schmitt, R.: International Photolysis Frequency Measurement and Model Intercomparison (IPMMI): Spectral actinic solar flux measurements and modeling, J. Geophys. Res., 108(D16), 8543, doi:10.1029/2002JD002891, 2003.

Bass, A. M. and Paur, R. J.: The ultraviolet cross-sections of ozone, I, The measurements, in: Atmospheric Ozone: Proceedings of the Quadrennial Ozone Symposium, edited by: Zerefos, C. S. and Ghazi, A. M., 606-610, Reidel, Boston, 1985.

Berk, A., Bernstein, L. S., and Robertson, D. C.: MODTRAN: A moderate resolution model for LOWTRAN 7, Tech. Rep. GLTR-89-0122, Geophysics Laboratory, Air Force System Command, Hanscom AFB, Massachusetts, 1989.

Bodhaine, B. A., Wood, N. B., Dutton, E. G., and Slusser, J. R.: On Rayleigh optical depth calculations, J. Atmos. Ocean. Technol., 16, 1854-1861, 1999.

Brewer, A. W.: A replacement for the Dobson spectrophotometer, Pure Appl. Geophys., 106-108, 919-927, 1973.

Browell, E. V., Ismail, S., and Grant, W. B.: Differential Absorption Lidar (DIAL) measurements from air and space, Appl. Phys.-B, 67, 399-410, 1998.

DeMajistre, R. and Yee, J.-H.: Atmospheric remote sensing using a combined extinctive and refractive stellar occultation technique,
2, Inversion method for extinction measurements, J. Geophys. Res., 107(D15), 4260, doi:10.1029/2001JD000795, 2002.

Dobson, G. M. B.: Observer's handbook for the ozone spectrophotometer, Ann. Int. Geophys. Year, 5, 46-89, 1957.

Grant, W. B., Fenn, M. A., Browell, E. V., McGee, T. J., Singh, U. N., Gross, M. R., McDermid, I. S., Froidevaux, L., and Wang, P.-H.: Correlative stratospheric ozone measurements with the airborne UV DIAL system during TOTE/VOTE, Geophys. Res. Lett., 25, 623-626, 1998.

Grant, W. B., Browell, E. V., Butler, C. F., Gibson, S. C., Kooi, S. A., and von der Gathen, P.: Estimation of Arctic polar vortex ozone loss during the winter of 1999-2000 using vortexaveraged airborne differential absorption lidar ozone measurements referenced to $\mathrm{N}_{2} \mathrm{O}$ isopleths, J. Geophys. Res., 108(D10), 4309, doi:10.1029/2002JD002668, 2003.

Greenblatt, G. D., Orlando, J. J., Burkholder, J. B., and Ravishankara, A. R.: Absorption measurements of oxygen between 330 and 1140 nm, J. Geophys. Res., 95, 18 577-18 582, 1990.

Gröbner, J. and Kerr, J. B.: Ground-based determination of the spectral ultraviolet extraterrestrial solar irradiance: Providing a link between space-based and ground-based solar UV measurements, J. Geophys. Res., 106, 7211-7217, 2001.

Kaye, J. A. and Miller, T. L.: The ATLAS series of Shuttle missions, Geophys. Res. Lett., 23, 2285-2288, 1996.

Livingston, J. M., Schmid, B., Russell, P. B., Eilers, J. A., Kolyer, R. W., Redemann, J., Ramirez, S. A., Yee, J.-H., Swartz, W. H., Trepte, C. R., Thomason, L. W., Pitts, M. C., Avery, M. A., Randall, C. E., Lumpe, J. D., Bevilacqua, R. M., Bittner, M., Erbertseder, T., McPeters, R. D., Shetter, R. E., Kerr, J. B., and Lamb, K.: Retrieval of ozone column content from airborne Sun photometer measurements during SOLVE II: Comparison with coincident satellite and aircraft measurements, Atmos. Chem. Phys. Discuss., 5, 243-286, 2005,

SRef-ID: 1680-7375/acpd/2005-5-243.

Lumpe, J. D., Bevilacqua, R. M., Hoppel, K. W., and Randall, C. E.: POAM III retrieval algorithm and error analysis, J. Geophys. Res., 107(D21), 4575, doi:10.1029/2002JD002137, 2002.

NASA: SAGE III algorithm theoretical basis document: Solar and lunar algorithm, Tech. Rep. LaRC 475-00-108, Vers. 2.1, NASA Langley Research Center, Hampton, Virginia, http://eospso.gsfc. nasa.gov, 2002.

Newman, P. A., Harris, N. R. P., Adriani, A., Amanatidis, G. T., Anderson, J. G., Braathen, G. O., Brune, W. H., Carslaw, K. S., Craig, M. T., DeCola, P. E., Guirlet, M., Hipskind, S. R., Kurylo, M. J., Küllmann, H., Larsen, N., Mégie, G. J., Pommereau, J.-P., Poole, L. R., Schoeberl, M. R., Stroh, F., Toon, O. B., Trepte, C. R., and van Roozendael, M.: An overview of the SOLVE/THESEO 2000 campaign, J. Geophys. Res., 107(D20), 8259, doi:10.1029/2001JD001303, 2002.

Newnham, D. A. and Ballard, J.: Visible absorption cross sections and integrated absorption intensities of molecular oxygen $\left(\mathrm{O}_{2}\right.$ and $\mathrm{O}_{2} \cdot \mathrm{O}_{2}$ ), J. Geophys. Res., 103, 28 801-28 816, 1998.

Noxon, J. F.: Nitrogen dioxide in the stratosphere and troposphere measured by ground-based absorption spectroscopy, Science, 189, 547-549, 1975.

Platt, U.: Differential optical absorption spectroscopy (DOAS), in: Air Monitoring by Spectroscopic Techniques, edited by: Sigrist, M. W., 27-76, Wiley, 1994. 
Pommereau, J. P. and Goutail, F.: $\mathrm{O}_{3}$ and $\mathrm{NO}_{2}$ ground-based measurements by visible spectrometry during Arctic Winter and Spring 1988, Geophys. Res. Lett., 15, 891-894, 1988.

Randall, C. E., Manney, G. L., Allen, D. R., Bevilacqua, R. M., Hornstein, J., Trepte, C., Lahoz, W., Ajtic, J., and Bodeker, G.: Reconstruction and simulation of stratospheric ozone distributions during the 2002 austral winter, J. Atmos. Sci., in press, 2005.

Roscoe, H. K., Freshwater, R. A., Wolfenden, R., Jones, R. L., Fish, D. J., Harries, J. E., South, A. M., and Oldham, D. J.: Using stars for remote-sensing of the Earth's stratosphere, Appl. Opt., 33, 7126-7131, 1994.

Russell, P., Livingston, J., Schmid, B., Eilers, J., Kolyer, R., Redemann, J., Ramirez, S., Yee, J.-H., Swartz, W., Shetter, R., Trepte, C., Risley Jr., A., Wenny, B., Zawodny, J., Chu, W., Pitts, M., Lumpe, J., Randall, C., and Bevilacqua, R.: Aerosol optical depth measurements by airborne Sun photometer in SOLVE II: Comparisons to SAGE III, POAM III and airborne spectrometer measurements, Atmos. Chem. Phys. Discuss., 4, 7291-7353, 2004, SRef-ID: 1680-7375/acpd/2004-4-7291.

Shettle, E. P. and Anderson, S. M.: New visible and near IR ozone absorption cross-sections for MODTRAN, in Proceedings of the 17th Annual Review Conference on Atmospheric Transmission Models, 8-9 June 1994, edited by Anderson, G. P., Picard, R. H., and Chetwynd, J. H., PL-TR-95-2060, (Special Reports No. 274), 335-345, Phillips Laboratory, Bedford, Massachusetts, 1995.

Shetter, R. E. and Müller, M.: Photolysis frequency measurements using actinic flux spectroradiometry during the PEM-Tropics mission: Instrumentation description and some results, J. Geophys. Res., 104, 5647-5661, 1999.

Shifrin, K. S.: Simple relationship for the Ångström parameter of disperse systems, Appl. Opt., 34, 4480-4485, 1995.

Swartz, W. H.: Quantifying photolysis rates in the troposphere and stratosphere, PhD thesis, University of Maryland, College Park, Maryland, 2002.
Swartz, W. H., Yee, J.-H., Vervack Jr., R. J., Lloyd, S. A., and Newman, P. A.: Photochemical ozone loss in the Arctic as determined by MSX/UVISI stellar occultation observations during the 1999/2000 winter, J. Geophys. Res., 107(D20), 8296 , doi:10.1029/2001JD000933, 2002.

Swinbank, R. and O'Neill, A.: A stratosphere-troposphere data assimilation system, Mon. Weather Rev., 122, 686-702, 1994.

Vervack Jr., R. J., Yee, J.-H., Carbary, J. F., and Morgan, F.: Atmospheric remote sensing using a combined extinctive and refractive stellar occultation technique, 3, Inversion method for refraction measurements, J. Geophys. Res., 107(D15), 4061, doi:10.1029/2001JD000796, 2002.

Vervack Jr., R. J., Yee, J.-H., DeMajistre, R., and Swartz, W. H.: Intercomparison of MSX/UVISI-derived ozone and temperature profiles with ground-based, SAGE II, HALOE, and POAM III data, J. Geophys. Res., 108(D22), 4697, doi:10.1029/2003JD003671, 2003.

Woods, T. N., Prinz, D. K., Rottman, G. J., London, J., Crane, P. C., Cebula, R. P., Hilsenrath, E., Brueckner, G. E., Andrews, M. D., White, O. R., VanHooiser, M. E., Floyd, L. E., Herring, L. C., Knapp, B. G., Pankratz, C. K., and Reiser, P. A.: Validation of the UARS solar ultraviolet irradiances: Comparison with ATLAS 1 and 2 measurements, J. Geophys. Res., 101, 9541-9469, 1996.

Yee, J.-H., Niciejewski, R., and Luo, M. Z.: Observations of $\mathrm{O}_{2}$ $\left({ }^{1} \Sigma\right)$ and $\mathrm{OH}$ nightglow during the ALOHA-90 campaign, Geophys. Res. Lett., 18, 1357-1360, 1991.

Yee, J.-H., Vervack Jr., R. J., DeMajistre, R., Morgan, F., Carbary, J. F., Romick, G. J., Morrison, D., Lloyd, S. A., DeCola, P. L., Paxton, L. J., Anderson, D. E., Kumar, C. K., and Meng, C.-I.: Atmospheric remote sensing using a combined extinctive and refractive stellar occultation technique, 1, Overview and proof-of-concept observations, J. Geophys. Res., 107(D14), 4213, doi:10.1029/2001JD000794, 2002. 